\title{
The Porcine Pulmonary Surfactant Protein A (pSP-A) Immunogenicity Evaluation in the Murine Model
}

\author{
Sandra de Cássia Dias ${ }^{1,3}$, Fernanda Lucio dos Santos ${ }^{2}$, Dirce Sakauchi ${ }^{2}$, Dmitri Iourtov ${ }^{2}$, Isaias Raw $^{3}$, \\ Flavia Saldanha Kubrusly ${ }^{3}$ \\ ${ }^{1}$ Engenharia de Bioprocessos-Campus Alto do Paraopeba, Universidade Federal de São João Del-Rei, Minas Gerais, Brazil; ${ }^{2}$ Divisão \\ Bioindustrial, Instituto Butantan, Sao Paulo, Brazil; ${ }^{3}$ Centro de Biotecnologia, Instituto Butantan, Sao Paulo, Brazil. \\ Email: kubruslyfs@butantan.gov.br
}

Received June $8^{\text {th }}, 2010$; accepted July $9^{\text {th }}, 2010$.

\begin{abstract}
This paper investigated the porcine surfactant protein A (pSP-A) immunogenicity in murine model. Many elegant studies about SP-A therapeutic applications are available however specific studies about its exogenous immunogenicity were not easily assumed. Therefore, we investigated the immunogenicity of this porcine protein in mice. The mice received pSP-A subcutaneously on days 0 and 7. The animals were observed during 90 days and the blood was collected on days 30, 60 and 90 for assessment the immunogenic potential of pSP-A. Some animals showed circulating antibodies above the screening cut point, which was calculated based on control mice sera signals. However, those antibodies were considered false positive read-outs by the performed competitive inhibition assay. Also no neutralizing antibodies were detected able to avoid the porcine protein ability to promote lipid aggregation. So far in this model, porcine surfactant protein-A could be considered not immunogenic.
\end{abstract}

Keywords: Immunogenicity, Porcine Surfactant Protein A, Anti-Drug Antibody, Murine Model

\section{Introduction}

Alveolar type II cells produce surfactant protein A, SP-A. This protein belongs to a group of soluble humoral pattern recognition receptors, called collectins, which modulate the immune response to microorganisms [1]. The primary unit of a collectin contains an amino-terminal collagen like domain and a carboxyl terminal lectin or carbohydrate recognition domain (CRD) united by a more hydrophobic neck. SP-A is assembled as hexamers of trimers. This super structure can bind, agglutinate, opsonize and neutralize many different pathogens and can also modulate the uptake of these microorganisms by phagocytic cells as well as the inflammatory and the adaptive immune responses. Recent data have also highlighted their involvement in clearance of apoptotic cells, hypersensitivity and a number of lung diseases [2-4].

Because of its ability to protect from infection by a wide variety of microorganisms and its capacity to regulate the inflammatory response SP-A might be used as a paradigm to develop drugs to prevent or treat lung infections [3]. Despite of a huge number of reports deals with the role of SP-A for pulmonary pathology and its probably use in lung disease treatment, very few reports mentioned the immunogenicity of SP-A after exogenous administration [5]. The SP-A high molecular mass, oligomeric structures and glycosylation can contribute for immunogenicity development, but theses properties are important to SP-A activity in vivo and should be maintained for therapeutics applications of this molecule.

Regulatory discussions about immunogenicity of therapeutic proteins represent today a central issue of biopharmaceuticals both by developers and by regulators cause an unwanted immunogenicity may lead to a loss of product efficacy besides severe side effects. These effects could develop more deleterious consequences to the patient (allergy, anaphylaxis, serum sickness, neutralization of the drug or native protein) [6,7].

Since we have been studying porcine lung as a raw material for the development of potential lung disease medicines, we purified porcine SP-A (pSP-A) as byproduct of lung surfactant production. The reduced number of reports about immunogenicity of exogenous SP-A administration prompted us to investigate the im- 
munogenicity of pSP-A in the murine model.

\section{Materials and Methods}

\subsection{Purification of Porcine Surfactant Protein A (pSP-A)}

The pSP-A was purified from a lung extract previously clarified. This extract is a waste from the main production. The short protocol involved an acid precipitation of the rejected extract before affinity chromatography (patent pending). LPS free pSP-A was obtained after the endotoxin removal by polymixin B-agarose (Pierce).

\subsection{Gel Filtration Chromatography}

Oligomerization was assessed by size exclusion chromatography. The pSP-A was loaded onto Superdex $200 \mathrm{HR}$ column (10/30) (Ge Healthcare) in $0.1 \mathrm{M}$ ammonium acetate- acetic acid buffer $(\mathrm{pH} 8.0)$. The flow rate was $0.3 \mathrm{~mL} / \mathrm{min}$ and the peaks were manually collected. The chromatography was calibrated using the molecular mass standards (Thyroglobulin-669 kDa, aldolase-158 kDa, albumin-66 kDa, ovalbumin-43 kDa, chymotrypsinogen$25 \mathrm{kDa})$.

\subsection{Protein Assay}

Protein concentration was determined using a bicinchoninic acid protein assay Kit (BCA; Pierce) using bovine serum albumin (BSA) as a standard.

\subsection{Gel Electrophoresis}

Purity of pSP-A were determined by $12.5 \%$ SDS-PAGE under reducing ( $\beta$-mercaptoethanol) and non-reducing conditions. Relative molecular masses of pSP-A were estimated using molecular mass standards run in parallel.

\subsection{Western Blot}

The pSP-A was resolved by SDS-PAGE (12.5\%) under reducing conditions and electroblotted from gel to the polyvinylidene difluoride membrane. After blocking, the membrane was incubated with rabbit anti-human SP-A polyclonal antibody from patients with rheumatoid arthritis or with mouse anti-human SP-A monoclonal antibody (HYB 238-04-S BIOPORTO) or with rabbit anti-porcine SP-A polyclonal antibody.

\subsection{Subcutaneous Administration of pSP-A}

Forty female Swiss mice (20-22 g) were housed in cages at room temperature $\left(22 \pm 1^{\circ} \mathrm{C}\right)$ and $12 \mathrm{~h}$ light-dark cycle. The Instituto Butantan Committee for Research and Animal Ethics approved the experimental protocol. Mice were separated in two experimental groups: control and treatment group. Treatment group-Twenty mice were injected subcutaneously (sc) with $100 \mu \mathrm{l}$ of pSP-A at dose of $5 \mathrm{mg} / \mathrm{kg}$ on days 0 and 7. Control group-Twenty mice were divided in two subgroups. Ten animals were sc injected with $100 \mu \mathrm{l}$ of saline on days 0 and 7 and the other ten were not injected. All animals were bled through the ophthalmic plexus on days 30,60 and 90 . The serum was separated and individually stored at $-20^{\circ} \mathrm{C}$.

\subsection{Screening for Circulating Antibodies against pSP-A}

The presence of anti-pSP-A polyclonal antibody in mice serum was investigated using an indirect ELISA assay. Wells were coated with $100 \mathrm{ng}$ of pSP-A in coating buffer (carbonate-bicarbonate $\mathrm{pH}$ 9.6) overnight at $4^{\circ} \mathrm{C}$ followed by blockage with $10 \%$ fetal calf serum in PBS-T. Control or treated mice sera diluted 10, 100 and 1000 times were added to search circulating antibodies against the protein. After that incubation, the second antibody (goat anti-mouse IgG peroxidase-conjugate from Sigma) was added. The optical density was read at $492 \mathrm{~nm}$ using a microtiter plate spectrophotometer (Multiskam). The screening cut point was calculated using the individual control sera results in triplicate obtained from the three bleedings and from the three used dilutions. ANOVA estimated the mean and the standard deviation results to be used in the parametric method: mean + 1.645SD [8].

\subsection{Competitive Immunoassay to Confirm the Positive Read-Outs against pSP-A}

A competitive immunoassay was performed to dis- criminate false positive to the actual positive read-outs. The same indirect ELISA procedure described above was used with exception that potential positive samples diluted 1:10 were previously incubated or not with pSP-A $25 \mu \mathrm{g} / \mathrm{mL}$, overnight at $4^{\circ} \mathrm{C}$. The assay was standardized using the rabbit polyclonal anti-pSP-A produced with Freund complete adjuvant (FCA) as the positive control diluted 1:2500 versus different pSP-A concentrations to built a calibration curve to establish the necessary amount of pSP-A to assure the specific inhibition or the specificity cut point. The chosen pSP-A concentration exceeded forty times the necessary amount. The percentage of signal inhibition is the ratio of pSP-A inhibited sample by uninhibited sample calculated by the formula:

$$
\begin{aligned}
& \text { percentage of the signal inhibition }= \\
& \qquad 100 \times 1-\frac{\text { study dtug inhibited sample }}{\text { unhibited sample }}
\end{aligned}
$$

\subsection{Screening for Neutralizing Antibodies (NAbs) against pSP-A}

The presence of NAbs was investigated in potential positive mice sera. The proposed assay verified the pSP-A dependent of $\mathrm{Ca}^{+2}$ ability to aggregate phospholipids 
vesicles. The following reagents were used: Instituto Butantan porcine lung surfactant solution $(125 \mu \mathrm{g} / \mathrm{mL})$ and pSP-A solution $(0.24 \mathrm{mg} / \mathrm{mL})$, both in assay buffer (5 mM Tris- $\mathrm{HCl} \mathrm{pH} 7.4$ plus $150 \mathrm{mM} \mathrm{NaCl}$ ); and aqueous $\mathrm{CaCl}_{2}$ solution $(2.42 \mathrm{mg} / \mathrm{mL})$. The lipid:pSP-A weight ratio was of 10:1 [9]. The assay was performed at $25^{\circ} \mathrm{C}$ in microplates. Phospholipids vesicles $(200 \mu \mathrm{L})$ were added in each well, and the turbidity was measured at $405 \mathrm{~nm}$ and monitored at $1 \mathrm{~min}$ intervals over $10 \mathrm{~min}$. Afterward, $10 \mu \mathrm{L}$ of controls and samples were added on the respective wells, and the turbidity monitored. Finally, $\mathrm{Ca}^{2+}(10 \mu \mathrm{L})$ was added to all and again monitored. For better specification: $\mathrm{pSp}-\mathrm{A}$ was the drug reference, the positive control was the rabbit anti-pSP-A polyclonal antibody made with adjuvant, the negative controls were the assay buffer, non-treated mice sera and the rabbit anti-bovine aprotinin polyclonal antibody and the samples were pSP-A treated mice sera of the second bleeding (high and lower responders). All controls and samples were diluting in a ratio of 1:9 in pSP-A solution. The reference was prepared as $9 \mu \mathrm{L}$ of the pSP-A solution plus $1 \mu \mathrm{L}$ of the assay buffer.

\subsection{Statistical Analysis}

Results are expressed as geometric means with the standard error of three independent observations. The data were statistically analyzed by ANOVA using the Prisma program (Graphpad Prism 5, San Diego, Califórnia). P < 0.05 was considered the level of statistical significance.

\section{Results and Discussion}

\subsection{Characterization of pSP-A}

The pSP-A was characterized in relation of its purity, oligomerization and identity (Figures 1 and 2). From those results it is important to highlight that the protein shows oligomeric forms (mainly hexamers) able to induce aggregation of phospholipid vesicles [10], one fundamental role of the protein in the intra-alveolar surfactant phospholipid organization [9]. For us, one important tool used to characterize its functionality.

After the subcutaneously injection of pSP-A in mice, we tried to develop a strategy for the assessment of antibody immune responses against pSP-A. First we performed a screening test for detecting the circulating antibodies. The screening cut point was calculated based on control mice sera response after each bleeding and for each dilution and the obtained value was $0.20 \pm 0.019$. The percentage of reactive samples was determined for each bleeding and for each dilution and they are 75, 40 and 30 for the first, 90, 85 and 70 for the second and 60, 30 and 20 for the third bleeding (Figure 3). Five animals $(04,08,10,13$ and 18$)$ were reactive in all bleeding and dilutions (Figure 3).
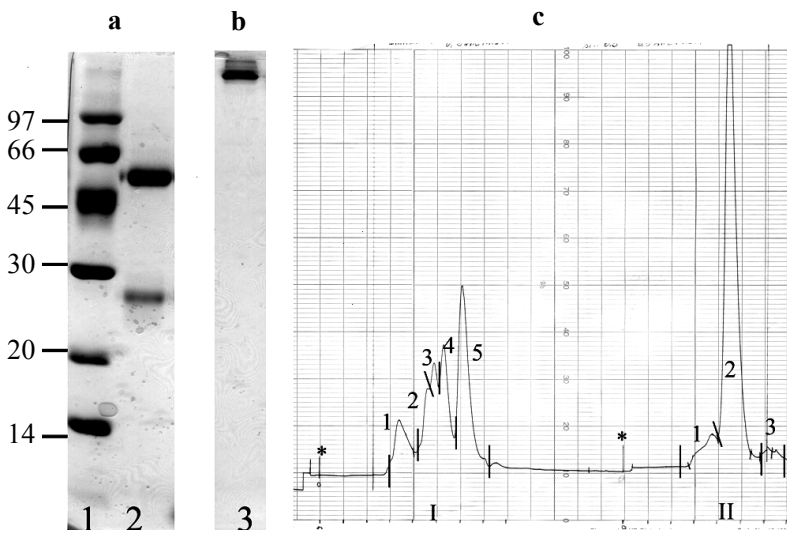

Figure 1. Characterization of pSP-A. Purity: $12.5 \%$ SDSPAGE (5 $\mu$ g/lane) under reducing (a) and non-reducing (b) conditions. (a) Lanes: 1-molecular markers. 2-pSP-A, (b) Lane: 1-pSP-A. Oligomerization (c): pSP-A (2.0 mg/200 $\mu \mathrm{l})$ was loaded onto Superdex 200 column (flow rate- $0.3 \mathrm{ml} / \mathrm{min}$, $2 \mathrm{~mm} / \mathrm{min}$ ). I-Molecular mass standards (1-thyreoglobulin, 2-aldolase, 3-albumin, 4-ovalbumin, 5-chymotripsinogen). II-pSP-A: 1-octadecamers, 2-hexamers, 3-monomers

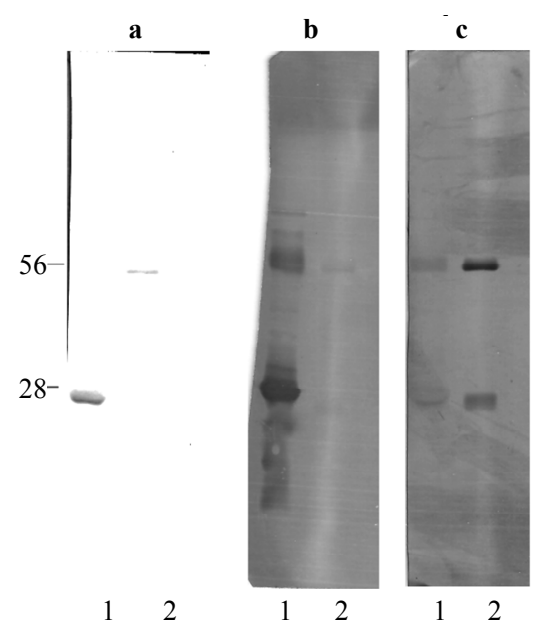

Figure 2. Characterization of pSP-A. Identity: Western Blot (10 $\mu$ g protein/lane), Lanes: 1-hSP-A, 2-pSP-A. (a)-mouse anti-human SP-A monoclonal antibody. (b)-rabbit anti-human SP-A polyclonal antibody from patients with rheumatoid arthritis and (c)-rabbit anti-porcine SP-A polyclonal antibody

Our second step of the program must discriminate false positive read-outs from the actual ones using a competitive immunoassay. The specificity cut point was determined using the rabbit pSP-A polyclonal antibody made with adjuvant as positive control when incubated or not with different pSP-A concentrations. When 0.625 $\mu \mathrm{g} / \mathrm{mL}$ pSP-A was added in the positive control, an inhibition of $58.18 \%$ was obtained (Figure 4). According results, the specificity cut point was defined as an inhibittion equal to or greater than $50 \%$. When 1:10 reactive samples from the second bleeding were incubated with 

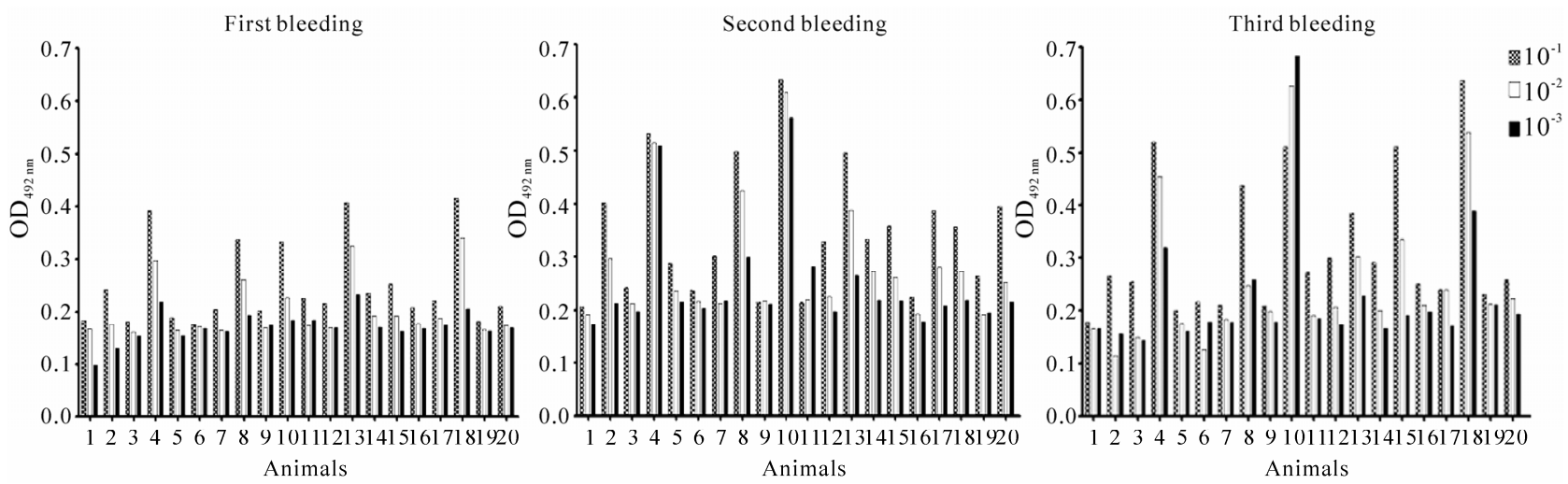

Figure 3. Humoral immune response to porcine SP-A administered subcutaneous rout. The animals were bled and their individual serum used for detection of anti-pSP-A circulating antibodies. The screening cut point (SCP) (0.20 \pm 0.019$)$ was obtained using the control group sera response

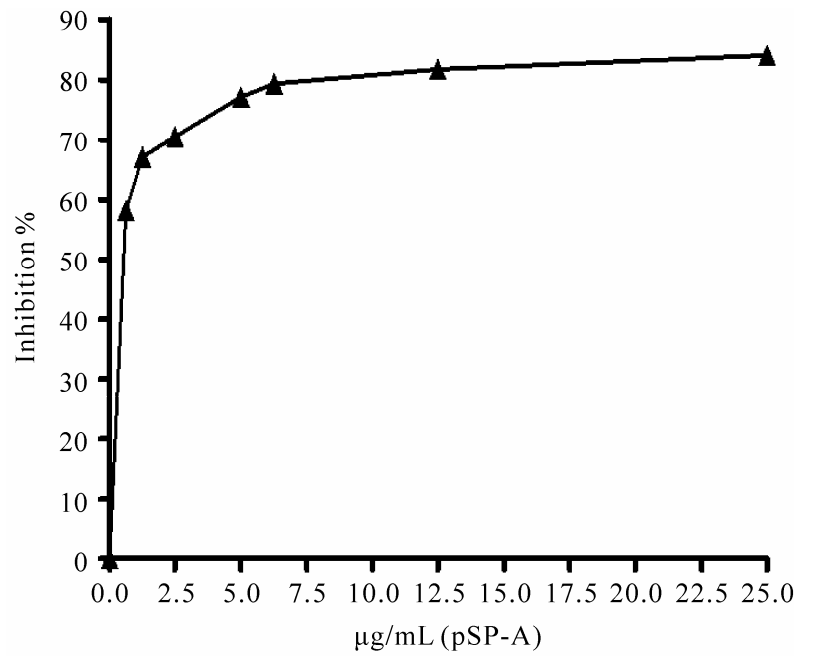

Figure 4. Competitive inhibition curve of rabbit anti-pSP-A antibody made with adjuvant. The antibody was incubated with different concentrations of PSP-A, and the inhibition quantified by Elisa. The specificity binding cut point was defined as inhibition equal to or greater than $\mathbf{5 0 \%}$

pSP-A $25 \mu \mathrm{g} / \mathrm{mL}$ (forty times greater to have drug excess), they showed different inhibitions, but they were less than 50\% for all of them (Figure 5). Thus, pSP-A treated mice did not develop specific antibodies against this protein.

Exogenous SP-A administration routes and treatment regime are still unknown. In this study we used highly immunogenic conditions, subcutaneous rout and two doses on days 0 and 7 with physiologic protein concentration. However, in the last bleeding we observed a decrease of the supposed anti-pSP-A antibodies. Theses results appointed to an antibody transient production and probably do not do have clinical relevance.

One last step was performed to conclude our validation program, we screened for NAbs in potential positive samples. For that purpose we used the pSP-A ability to

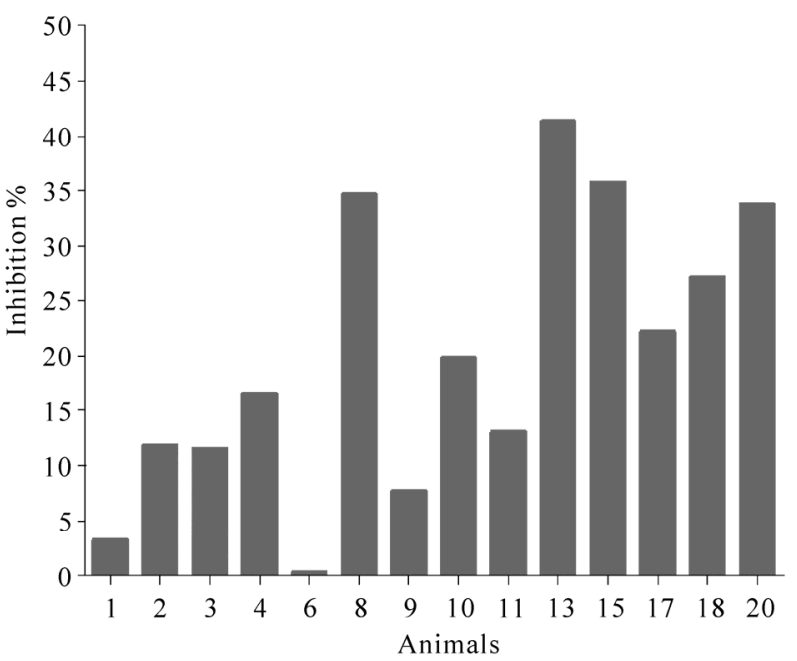

Figure 5. Competitive inhibition assay. Mice second bleeding individual serum (1:10) were incubated with pSP-A (25 $\mu \mathrm{g} / \mathrm{mL})$. The protein concentration was forty times greater than used in the inhibition curve. Elisa quantified the inhibition

aggregate phospholipid vesicles [11]. Ruano et al. (1996) showed that after $\mathrm{Ca}^{2+}$ addition the light absorbance of SP-A/lipid aggregates increases 20-25\% [9]. We had similar results (Figure 6). Moreover, any mice treated sera did not affect the p-SP-A ability to phospholipids aggregation, which means we did not detected NAbs against p-SP-A (Figure 6). All reactive samples are false positives.

Our pSP-A immunogenicity evaluation led us to conclude that at least for the murine model the porcine protein has no immunogenic potential.

Are those results enough to propose p-SP-A as one safety and efficacy drug for human lung disease treatment? Or we must consider the predictive value of animal models for the evaluation of immunogenicity in humans to be usually low [8]. So, what to do? 

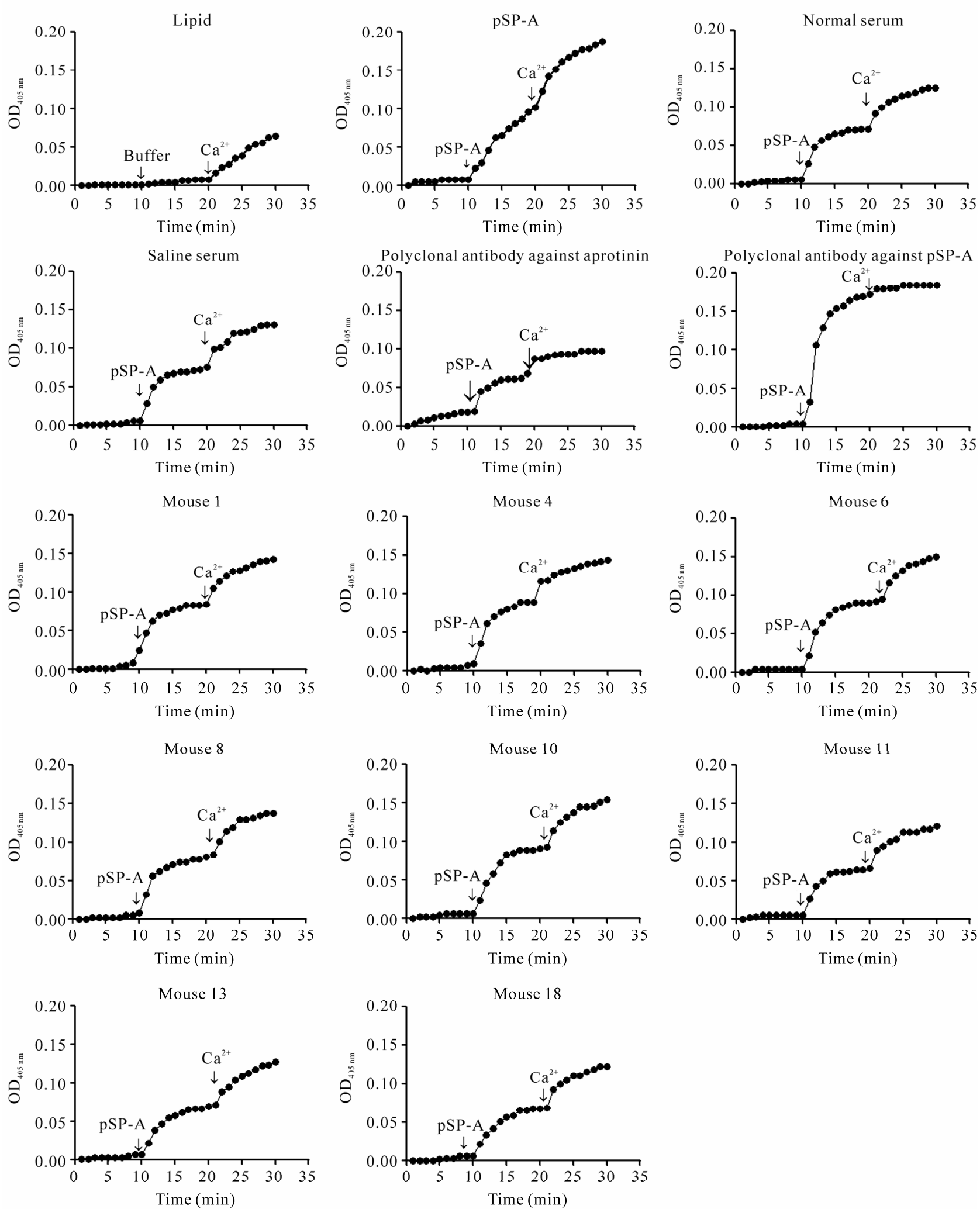

Figure 6. Assay for detect neutralizing antibodies (Nabs) in serum of mice treated with pSP-A. The Nabs must destroy protein ability to lipid aggregation. Samples and references were filled with $125 \mu \mathrm{g} / \mathrm{mL}$ phospholipids. After 10 min, buffer, samples, positive and negative controls were added in respective wells. $\mathrm{Next}, \mathrm{Ca}^{2+}(1 \mathrm{mM}$ final concentration) was added in all wells 


\section{Acknowledgements}

Thanks to Dr. RMF Piazza for kindly donation of the reagents human SP-A and human SP-A antiserum.

Support: FAPESP, PRONEX, SADIA, Fundação Butantan.

\section{REFERENCES}

[1] P. Waters, M. Vaid, U. Kishore and T. Madan, "Lung Surfactant Proteins A and D as a Pattern Recognition Proteins," Advances in Experimental Medicine Biology, Vol. 653, December 2009, pp. 74-97.

[2] N. Palaniyar, J. Nadesalingam, H. Clark, M. J. Shih, A. W. Dodds and K. B. Reid, "Nucleic Acid is a Novel Ligand for Innate, Immune Pattern Recognition Collectins Surfactant Proteins A and D and Mannose-Binding Lectin," The Journal of Biological Chemistry, Vol. 279, No. 31, May 2004, pp. 32728-32736.

[3] A. Haczku, "Protective Role of the Lung Collectins Surfactant Protein A and Surfactant Protein D in Airway Inflammation," The Journal of Allergy and Clinical Immunology, Vol. 122, No. 5, November 2008, pp. 861-879.

[4] M. E. Famuyide, J. D. Hasday, H. C. Carter, K. L. Chesko, J. R. He and R. M. Viscardi, "Surfactant Protein-A Limits Ureaplasma-Mediated Lung Inflammation in a Murine Pneumonia Model," Pediatric Research, Vol. 66, No. 2, August 2009, pp. 162-167.

[5] S. G. Kremlev and D. S. Phelps, "Surfactant Protein A Stimulation of Inflammatory Cytokine and Immunoglobulin Production," American Journal Physiology,
Vol. 267, No. 6, December 1994, pp. L712-L719.

[6] G. Schernthaner, "Immunogenicity and Allergenic Potential of Animal and Human Insulins," Diabetes Care, Vol. 16, Suppl. 3, December 1993, pp. 155-165.

[7] E-V. Jahn, C. K. Schneider, "How to Systematically Evaluate Immunogenicity of Therapeutic ProteinsRegulatory Considerations," New Biotechnology, Vol. 25, No. 5, June 2009, pp. 280-286.

[8] G. Shankar, V. Devanarayan, L. Amaravadi, Y. C. Barrett, R. Bowsher, D. Finco-Kent, M. Fiscella, B. Gorovits, S. Kirschner, M. Moxness, T. Parish, V. Quarmby, H. Smith, W. Smith, L. A. Zuckerman and E. Koren, "Recommendations for the Validation of Immunoassays Used for Detection of Host Antibodies against Biotechnology Products," Journal of Pharmaceutical and Biomedical Analysis, Vol. 48, No. 5, December 2008, pp. 1267-1281.

[9] M. L. F. Ruano, E. Miguel, J. Perez-Gil and C. Casals, "Comparison of Lipid Aggregation and Self-Aggregation Activities of Pulmonary Surfactant Associated Protein A," Biochemical Journal, Vol. 313, Part 2, January 1986, pp. 683-689.

[10] F. Sánchez-Barbero, J. Strassner, R. García-Canero, W. Steinhilber and C. Casals, "Role of the Degree of Oligomerization in the Structure and Function of Human Surfactant Protein," The Journal of Biological Chemistry, Vol. 280, No. 9, March 2005, pp. 7659-7670.

[11] H. P. Haagsman, A. Hogenkamp, M. van Eijk and E. J. Veldhuizen, "Surfactant Collectins and Innate Immunity," Neonatology, Vol. 93, No. 4, June 2008, pp. 288-294. 